\title{
Research on Promotion of Young Teachers' Ability in Private Universities
}

\author{
Li Yan \\ School of English Language and Culture, Xi'an Fanyi University, Xi'an, China \\ liuyihanly@163.com
}

Keywords: Young teachers, Ability promotion, Private universities.

\begin{abstract}
Under the circumstances of vocational education, this paper was carried out to investigate current situation of young teachers' ability development in private universities through the methods of questionnaire and interview. The result shows that young teachers can not fully understand components of teachers' ability, they are not sensitive enough to judge the trend of higher education development and their abilities are unbalanced. Based on this, the author puts forward three-way linkage mechanism, which is made up of three factors including the private university, secondary school and young teachers, to promote teachers' ability so as to improve the teachers' overall quality and accelerate the pace of vocational education development of private universities in the face of new trend of higher education reform.
\end{abstract}

\section{Introduction}

in March,2014, Lu Xin,vice-minister of Ministry of Education, stated on the China' s Development Summit Forum that more than 600 local undergraduate colleges and universities would transfer to the development of applied technology and vocational education, and in May, The Decision to Accelerate the Development of Modern Vocational Education was issued by The State Council. The decision that some universities should transfer to the development of the applied technology and focus on vocational education development was clearly emphasized.[1] Under such circumstances, it is imperative that private universities, as an indispensable components of higher education, turn to develop applied technology, which is the demand of the national higher education as well as the need for self-development of private universities. Facing the transformation development of higher education, teachers in private universities will be confronted with new challenges and high requirements of vocational education, that is, teachers need to improve their vocational education teaching ability and professional knowledge gradually by the continuous learning and researches based on the characteristics and requirements of education, which means teachers need to grow into the expert from the novice through life-long learning[2]. Therefore, how to help teachers improve their abilities and qualities has become one of an important issues under the circumstances of vocational education for private universities. This research analyzes current situation of young teacher's professional development in private universities through questionnaire and interviews and explores ability promotion strategies for young teachers so as to accelerate the pace of vocational development and promote teaching quality of private universities.

\section{Investigation of young teachers' ability in private universities}

Private universities, which are regarded as an integral part of tertiary education, have been developing for several decades in China. Although they have achieved great success in the perspective of faculty construction. However, because of limitations of private universities in process of development, there is much room to be further improved, especially overall quality of teaching staff. How to improve teachers' competence to meet the development needs of private universities and adapt to higher education development has attracted more and more scholars and education workers' attention.

In order to understand status quo of teachers' ability in private universities and find out possible 
problems to hinder the young teachers' professional development, the research group constructed teachers' ability framework including teaching ability, research ability, vocational ability and self-development ability(Fig.1)based on the ability model of teacher professional development[3] and teacher's ability system[4] and designed the questionnaire of ability development for young teachers. With 120 questionnaires returned and 8 teachers interviewed from 5 private universities, both simple random sampling and interviews were applied. The data results can serve as reliable support for scientific analysis.

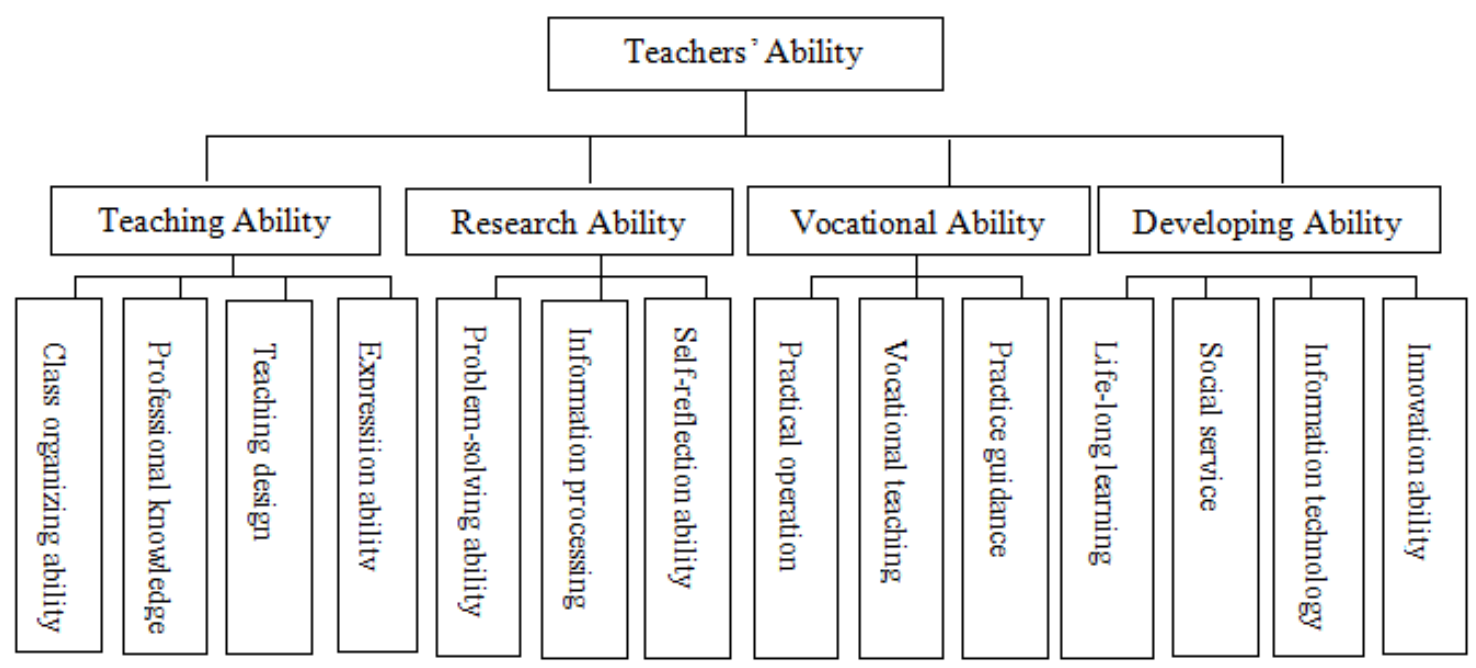

Fig. 1 Teachers'Ability Framework

\subsection{Analysis of basic data}

\section{Basic information of research objects}

The basic information of 120 young teachers is as follows. Female teachers count for $68.3 \%$ and take up the majority of young teachers in private universities. Respectively $87.5 \%$ and $86.7 \%$ young teachers hold master's degree and and junior professional title. Most of objects have been teachers for 5 to 8 years. All teachers, whose teaching courses cover 6 main subject disciplines including literature,management, economics etc., come from pilot universities of transformation and development in Shaanxi Province, with more than 10,000 students enrolled. Therefore, information from the questionnaire can actually reflect current situation of young teachers' ability development.

\section{Young teachers' perception of teachers' ability}

The formation of teachers' ability, teachers' core competence and the ability urgently improved are investigated in this part. Most young teachers believe teachers' ability includes teaching ability (taking up 67.5\% young teachers) and research ability (taking up 73.3\% young teachers), while vocational ability and developing ability are not received enough attention, only taking up 45.8\% and $50 . \%$ respectively. With regard to understanding of teachers' core competence, most teachers think research ability and teaching ability should be the much more important than developing ability and vocational ability. Besides, young teachers are eager to improve their research ability instead of developing ability and vocational ability. This shows that young teachers' perception of teachers' ability is far from comprehensive. They pay too much attention to the importance of research ability, while vocational ability and developing ability are not given highly concerned.

\section{Current situation of young teachers' ability development}

According to the survey, teachers have burning desire to attend various professional development training activities; however, only $44.2 \%$ teachers have clear ability promotion plan and only $28.3 \%$ young teachers often attend seminars on the development trend of higher education. Furthermore, few teachers put the plan into practice to improve their abilities, and the data shows only $31.7 \%$ teachers have the experience of working in enterprises and teachers attending innovation training only take up 20 percent. In terms of teachers' developing ability, half of the teachers are good at 
learning by themselves, while they have relatively poor ability in applying modern education technology and have weak awareness in social service. According to the interview, there are two reasons. one is universities can not provide enough training programs for teachers to improve their abilities, and the other is closely concerned with teachers' assessment, in other words, in private universities, research assessment is given undue emphasis rather than teachers' vocational ability.

\subsection{Overall analysis}

Teachers' ability is the individual psychological characteristic in the process of teaching which directly or indirectly influences the quality and accomplishment of teaching activities[5]. With the development of education, the teacher's role is changed and teachers' competence is endowed with new connotations. Therefore, it is a dynamic and multiplex combination pattern. The investigation result shows that teachers in private universities paid much attention to the research and teaching level and neglect the importance of vocational and developing ability, especially practical guidance and innovative ability under the circumstances of vocational development of higher education.

It is unbalanced in ability development for young teachers in private universities. They generally value the importance of research outcome and ignore the value of practical ability, which leads to the unbalanced ability development. The main reason is that the assessment standard of private universities is the same as that of public universities, in other words, teachers' assessment is directly linked with teachers' research output and title promotion, while teachers' vocational ability takes up little proportion. Besides, the motivation for young teachers' self- improvement mainly comes from the external factors, such as title promotion, universities assessment instead of the embodiment and sublimation of teacher's own value, which is proved by the interviewees, as one young teacher said: "research and professional title are the foundation of decent life to be a teacher in the university."

Since the $21^{\text {st }}$ century, a series of documents issued, for instance, The National Medium and Long-term Education Reform and Development Plan Outline(2010-2020),The Decision to Accelerate the Development of Modern Vocational Education, marked transformation development and vocational education had become keywords of a new round of higher education reform. This has set higher requirements for the teachers in private universities. However, interview and survey results show that young teachers have weak and insensitive awareness, unclear promotion plan and insufficient promotion motivation in face of the new situation of higher education reform.

\section{Ability promotion strategies for young teachers in private universities}

To adapt to the needs of social development, competence is the core element of teachers in private universities to foster applied talents, so the competence promotion is not only closely related to the individual professional development of young teachers, but also to the development of talents quality and private universities. Therefore, the author puts forward a three-way linkage mechanism to accelerate young teachers' ability promotion in private universities.

This mechanism covers three factors including private universities, secondary school and young teachers. For the private universities perspective, on the one hand, they should hold seminars on the analysis of higher education policies to help teachers understand the development trend of tertiary education and the idea of private universities development, establish their ownership and stimulate the creativity of young teachers so as to develop themselves together with universities they are in. On the other hand, universities should increase funds to support young teachers professional development and establish training platform to create a harmonious external environment for young teachers growth. Moreover, rational evaluation system should be built and reasonable goals should be made for young teachers to arouse their enthusiasm of self-development.

At the secondary school perspective, they should actively implement deep university-enterprise cooperation to explore more opportunities for young teachers to improve their vocational ability and guidance ability. Meanwhile, more experts from enterprises should be invited to help develop teachers' vocational ability through lectures and practical guidance.

For the young teachers, they should realize the essence of autonomous development and actively overcome difficulties in the process of self-promotion because whether they have independent 
development consciousness is the key to the improvement of their competence. Therefore, young teachers should always maintain the enthusiasm of self-development on the basis of self-reflection, follow the frontier theory of subjects, attempt to apply modern education technology to their teaching practice and perfect their teaching philosophy so as to promote their ability under the circumstances of vocational education.

\section{Conclusion}

In short, the young teachers' ability in private universities directly affects the quality of applied talents training. It means young teachers' ability is the foundation of education development of private universities. How to improve young teachers' ability is an important project for private universities. Moreover, the growth of young teachers is not achieved overnight, so it needs strong support from universities to create a good external environment as well as unremitting efforts from young teachers themselves.

\section{Acknowledgement}

This research was financially supported by Education Teaching Reform Fund of Shaanxi Province(Grant NO. 17BY111) and the periodical research achievement of research team of Xi'an Fanyi University(Grant NO. XFU17KYTDC09).

\section{References}

[1] The Decision to Accelerate the Development of Modern Vocational Education, The State Council, 2014.5

[2] Tang Xiaomin and Cheng Songzhou, Discussion on the Present Situation and Development Countermeasure of Higher Vocational College Teachers' Specialization, Education Exploration, vol.6, pp.89-90,2009.

[3] Wang Lizhen, The Construction of Ability Model for Teachers' Professional Development, Theory and Practice of Education, vol.22, pp. 36-40, 2013.

[4] Jing Ying and Wang Ailin, The Exploration of Teacher's Ability System in New Century,Theory and Practice of Education, vol.10, pp.38-42, 2012.

[5] Li Taisheng, The Improvement of Foreign Language Teachers' Practical Teaching Ability in Vocational Colleges, Vocation and Education,Vol.33,pp.71-73,2015. 